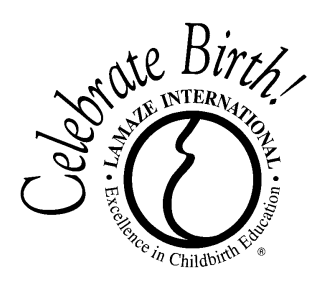

\title{
Charlotte's Birth
}

\author{
Laure Sinnhuber-Giles
}

\begin{abstract}
A young mother shares her story of normal birth at home. Her story includes a thank-you letter written to Ina May Gaskin, who shared her wisdom in her book, Ina May's Guide to Childbirth.
\end{abstract}

Journal of Perinatal Education, 17(3), 4-6, doi: 10.1624/105812408X329566

Keywords: home birth, normal birth, birth satisfaction, natural birth

Do you have a birth story that illustrates the power of normal childbirth and encourages women to give birth with confidence? We invite you to submit your story for possible publicatio in JPE. Please send your story or query to Judith Lothian, Associate Editor (Jalothian@aol.com). Also, check out the "Giving Birth with Confidence Blog" and "Normal Birth Forum" links at Lamaze International's Web site (www.lamaze.org).
CHARLOTTE'S BIRTH - FEBRUARY 17, 2006

My pregnancy had been straightforward, so I was convinced that by having my baby at home, with the help of a skilled midwife and the support of my husband Jonathan, I would be able to be most relaxed and, therefore, feel a minimum of discomfort. I wanted this day to be fun, and so it turned out to be!

The day before Charlotte was born, I attended a little farewell party that concluded the Spanish class I was taking at the time. As I talked about the upcoming birth of my baby to one of my classmates, she told me the story of the birth of her three children and how easy and fast things had been for her. She talked in such a relaxed way, and the class had been so enjoyable, I remember leaving the Spanish institute with a feeling of well-being.

It was a sunny and mild winter day, and the remains of snow were melting away as I walked home that afternoon. I remember arriving at home feeling hot, so I changed clothes and put on a long, comfortable T-shirt to potter around the house. In the evening, because I knew Jonathan was going out with some friends, I made myself a nice dinner (sausages, brown rice, and vegetables), and then I sat down comfortably to read one of Marcel
Pagnol's books. I remember laughing because the story was so funny. As I got up to get ready for bed just after 10:00 p.m., I realized I had lost my mucus plug. When I looked up what this actually meant in one of my pregnancy guides, I read that labor could start any time soon, or maybe not for another 2 weeks. I was excited by this event and wanted to tell Jonathan, but I thought there was no need to get overexcited and that I should now get a good night's sleep.

I was fast asleep when Jonathan came in through the door just after midnight. As the hinges squeaked, I woke up and felt what turned out to be my first contraction. It was as if my body and my daughter had waited until Jonathan was with us to start their work. At the time, I thought I just needed to go to the bathroom. I went to the kitchen for a glass of water, when my water broke. I told Jonathan that this could mean labor was either imminent or perhaps not yet. We thought we would go to bed and rest. As I went back to the bathroom for a moment, Jonathan quickly fell asleep.

I took a shower before going back to bed, but I noticed that each time I faced the spout to rinse myself, my lower back hurt, so I turned around and let the hot water massage that area, which provided 


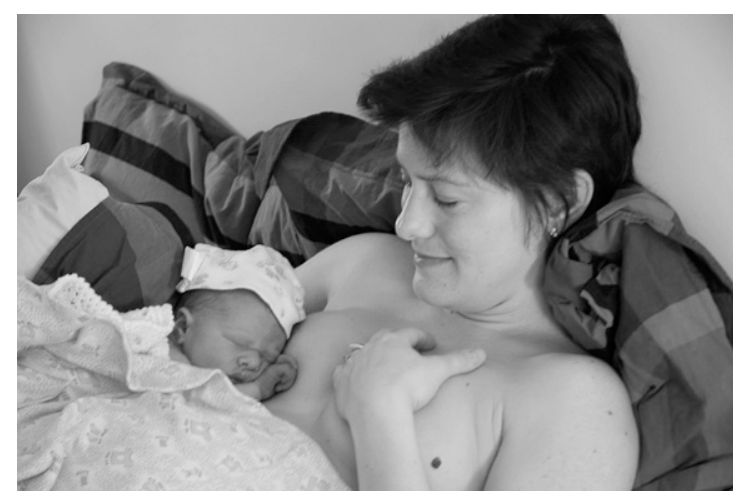

Charlotte and Laure, skin to skin.

immediate relief. At some stage, I felt my blood pressure drop from all the time spent in the hot water, so I got out of the shower. Because I felt hot and slightly dizzy, I lay down on the tiled bathroom floor on which I had scattered a few towels. I felt relieved and put my nightdress back on. On my way to bed, I suddenly felt that the mattress was going to be too soft and that I needed to lie down on the bedroom floor. At this stage, Jonathan woke up and saw that my behavior was somewhat different from usual. $\mathrm{He}$ knew we were on the way to meet our baby.

From then on, I lost my perception of time. I remember I felt very comfortable in the small bathroom; I had a great sense of privacy. It was clean and had no windows, so I didn't fear that I would disturb anybody by breathing loudly. I used the bathroom furniture to lean on, finding the most comfortable position to help my body do its work. I later felt like using my voice to help my body. Each time a contraction started, my voice vocalized the sensation, and I remember making a conscious effort to keep my voice low in order to help my cervix open. Jonathan rubbed my lower back, which provided me with great relief, and later he brought me some juice because I felt I needed some sugar to keep on working. My sense of smell and taste felt heightened; I asked Jonathan to try to get rid of his beer breath, and later I felt I didn't like the taste of the water from the filtering jug. The first thing I recognized when Marcy, my midwife, arrived around 3:00 a.m., was her perfume.

I don't know when I actually entered the socalled "pushing stage" of labor because, from the beginning, the entire process felt like pushing. When I moved from the bathroom to the bedroom, I remember not only feeling somewhat embarrassed because I had a small poop accident but also feeling all right because I knew it was natural and that Jonathan was handling things just fine. Sitting on the
Each time a contraction started, my voice vocalized the

sensation, and I remember making a conscious effort to keep

my voice low in order to help my cervix open.

physiotherapy ball felt really good because it provided me with great support and with enough give at the same time. Jonathan sat behind me to immobilize the ball at the foot of our bed. At some stage, Marcy and her assistant, Loretta, suggested I get up, and they helped me to take off my nightdress. I remember picturing myself as a big tree: My legs were the roots, my body the trunk, and my head the branches. For some reason, this picture helped. Later, I squatted, facing Marcy and leaning on Jonathan, who sat behind me at the foot of our bed. I remember it didn't matter whether I could see anything; the room was dimly lit, and I felt comfortable. All I needed was to concentrate on feeling. The last hour of pushing was the hardest for me. I found it harder to relax, although I felt everything was going to be fine because Marcy and Loretta were there. I remember realizing how this later stage of labor was taking proportionally more time than the first stage. I remember telling myself, "Right, let's finish the job." Then I felt the baby's head crowning, and a moment later-at 4:34 a.m. - she was with us. She smelled of chamomile flowers as we unfolded her and found that we had a little girl.

I remember how relaxed we all were and how peaceful it was in the bedroom after Charlotte arrived. Marcy took care of the little tear I had while we chatted with Loretta. I called my mum, who was walking around Paris at the time, and she noticed how my voice was still hoarse from all the recent use I had made of it. Later, Loretta helped me take my first postpartum shower, which felt fantastic. She dried me up like a baby. Then Jonathan and I had some breakfast in bed. Most probably the best pain au chocolat I ever ate! Marcy and Loretta left around 9:00 a.m., and we then shared our first moments as parents with our little Charlotte.

\section{THANK-YOU LETTER TO INA MAY GASKIN}

Dear Ina May,

To prepare myself to give birth, my midwife, Marcy, recommended I read your Ina May's Guide to Childbirth. This was the best advice I received,

Sitting on the physiotherapy ball felt really good because it provided me with great support and with enough give at the same time. 
My daughter's birth reminded me that I can trust myself. I can

trust my gut feeling that I am able to put together the right set

of prerequisites to succeed in whatever I wish to do.

and I would like to tell you how grateful I am that you wrote your book.

The further I read your book, the less I feared giving birth. As I closed your book, I felt ready and confident that things would work out as best as they could. And they did.

Of course, a woman's body is made to give birth; yet, it was hard to ignore the general consensus: It is masochistic to want to give birth out of a hospital. Your book helped me to rationalize my gut feeling, which was that my body could relax much better at home and, therefore, avoid unnecessary tensions that would lead to pain. All I needed was my husband to help me during labor and a skilled midwife to help me birth the baby. Consequently, I experienced my daughter's birth as I had wished: as the celebration of her arrival.

Before being mentally prepared, I remember wondering how I was going to feel the day I realized I was in labor. I was slightly worried that I would feel like crying because it would be all too much for me. When I actually was in labor, I never once felt stressed. All I needed to do was to follow my body's cues.

Your book's chapters on "sphincter law," on the "forgotten vaginal powers," and on letting the "monkey do it" were particularly helpful to me. I also found that the pictures showing women with a happy face while birthing had a strong influence on me. The Farm's statistics were also very helpful to prepare myself.

My daughter's birth reminded me that I can trust myself. I can trust my gut feeling that I am able to put together the right set of prerequisites to succeed in whatever I wish to do. It was a truly empowering experience.

Thank you so much, Ina May!

- Laure

LAURE SINNHUBER-GILES graduated from the Sorbonne in Paris in 1995 and continued her language studies in Heidelberg, Germany, and Kyoto, Japan. From 1999-2005, she lived in London and held various positions in international media. In 2006, she moved to New York City and, with the help of a midwife, gave birth at home to her daughter, Charlotte. This pivotal moment led to Sinnhuber-Giles's involvement in the advocacy group, Choices in Childbirth, which strives to help women make better-informed maternity-care decisions. She hopes more women will stop fearing birth and start reclaiming this wondrous life transition.

\section{Call for Manuscript Reviewers}

The editors of The Journal of Perinatal Education (JPE) are seeking to increase their pool of qualified manuscript reviewers. Manuscript reviewers play a vital role not only in appraising and helping an author strengthen a manuscript, but also in shaping the credibility and reputation of the journal.

The JPE is the leading peer-reviewed journal specifically for childbirth educators. Through evidencebased articles, the journal keeps perinatal health professionals informed about research and its implications for practice. The editors of JPE are committed to the timely publication of manuscripts that provide credible evidence to promote, support, and protect normal birth through education and advocacy. As such, the identification and selection of reviewers who have expertise and interest in the topics appropriate to each manuscript are essential elements in ensuring a timely, productive, peer-review process.

If you are interested in serving as a reviewer, please submit your contact information along with a brief biosketch or $\mathrm{CV}$, including details regarding your degree and present position, fields of interest, editorial experience, publications from the last 5 years that reflect your expertise, and at least five keywords that reflect your clinical or research interests to Dr. Wendy Budin, Editor-in-Chief of JPE (wendy.budin@ nyu.edu). 